\title{
Sensitisation to airborne allergens as a risk factor for allergic rhinitis and asthma in the Polish population
}

\author{
Agnieszka Lipiec ${ }^{1}$, Adam Sybilski ${ }^{1,2}$, Jarosław Komorowski ${ }^{1}$, Konrad Furmańczyk ${ }^{1,3}$, Andrzej Namysłowski ${ }^{1}$, \\ Wojciech Zieliński ${ }^{1,4}$, Filip Raciborski ${ }^{1}$, Artur Z. Białoszewski ${ }^{1}$, Bolesław Samoliński ${ }^{1}$
}

'Department of the Prevention of Environmental Hazards and Allergology, Medical University of Warsaw, Warsaw, Poland 2Department of Paediatric and Neonatology, Central Clinical Hospital of the Ministry of Internal Affair, Warsaw, Poland ${ }^{3}$ Department of Applied Mathematics, Faculty of Applied Informatics and Mathematics, Warsaw University of Life Sciences, Warsaw, Poland

${ }^{4}$ Department of Econometrics and Statistics, Warsaw University of Life Sciences, Warsaw, Poland

Adv Dermatol Allergol 2020; XXXVII (5): 751-759

DOI: https://doi.org/10.5114/ada.2019.84231

\begin{abstract}
Introduction: The patterns of sensitisation to airborne allergens and their association with allergic diseases have been analysed in different geographical regions.

Aim: To analyse the impact of sensitisation to airborne allergens on allergic rhinitis (AR) and asthma in different age groups of the Polish population.

Material and methods: Completed questionnaires of 18,617 subjects (53.8\% females), collected within the ECAP, a cross-sectional multicentre study, were analysed. Three groups of respondents were included: 6-7-year-olds (24.2\%), 13-14-year-olds (25.4\%), 20-44-year-olds (50.4\%). The clinical part (an anamnesis, physical examination, spirometry, skin prick tests and an assay of major airborne allergen-specific IgE) was attended by $25.7 \%$ of the respondents.

Results: The AR was most strongly related to sensitisation to Dermatophagoides pteronyssinus, with the highest odds ratios of 10 in two younger groups and of 16 for persistent AR in children. It was also the most important risk factor for allergic asthma, with odd ratios from 8.34 in children to 6.40 in adolescents. Sensitisation to grass pollen allergens was a major risk factor for both AR, with odds ratios from 9.16 in adults to 7.87 in adolescents, and asthma, with odds ratios from 6.16 in adolescents to 5.67 in adults.

Conclusions: AR and asthma shared common risk factors, independently of age. Sensitisation to airborne allergens was significantly associated with asthma and, even more strongly, with AR, across all age groups. The AR was the strongest risk factor for allergic asthma in the youngest group. Persistent AR increased asthma risk more than intermittent AR in all age groups.
\end{abstract}

Key words: allergic rhinitis, asthma, airborne allergens, sensitisation.

\section{Introduction}

It is agreed that atopy is an important risk factor for allergic rhinitis and asthma; however, to what degree it affects the development of these diseases is still under debate. Published papers have analysed various aspects of this association, such as differences in sensitisation patterns and their association with allergic diseases as well as environmental interactions between sensitisation and the development of the disease [1-6]. As the major airborne allergens vary with geographical area [7, 8], the associations between sensitisation and allergic rhinitis

and asthma have been investigated in populations from various regions in the world, including Europe [9-18]. The present extensive epidemiological study of these associations in the Polish population follows this line of research.

\section{Aim}

The aim of the study was to analyse the impact of sensitisation to airborne allergens on allergic rhinitis and asthma in different age groups of the Polish population.

Address for correspondence: Agnieszka Lipiec MD, PhD, Department of the Prevention of Environmental Hazards and Allergology, Medical University of Warsaw, 1a Banacha St, 02-507 Warsaw, Poland, phone: +48 22599 20 39, e-mail: alipiec@wum.edu.pl Received: 18.03.2019, accepted: 24.03.2019. 


\section{Material and nethods}

The ECAP was a cross-sectional multicentre study that used complete ECRHS II and ISAAC questionnaires, translated into Polish and validated in a pilot study. Subjects living in the eight large Polish urban centres (Warsaw, Lublin, Białystok, Gdansk, Poznan, Wroclaw, Katowice, Krakow) and one rural area (Zamosc and Krasnystaw districts) were included in the study. The study group was randomised and stratified based on the personal identity number (PESEL), which covers the entire population of Polish residents. A total of 20,454 respondents were enrolled; however, 18,617 questionnaires (including 10,011 (54\%) questionnaires completed by females) met the ultimate quality assessment criteria. The study included three groups of respondents, namely, 6-7-year-old children (24.2\%, $n=4,510), 13-14$-year-old adolescents (25.4\%, $n=4,721)$, and 20-44-year-old adults (50.4\%, $n=9,386)$.

The questionnaire-based survey was conducted via computer-assisted personal interviewing (CAPI) with the use of personal digital assistant (PDA) technology. Completed questionnaires were automatically transferred via General Packet Radio Service (GPRS) to a central unit to form a database for analysis. In the questionnaire, the presence of allergic rhinitis (AR declared) was identified with the question: "Do you suffer from any nasal allergies, including runny nose due to allergy to plant pollen (hay fever)?" The presence of asthma (asthma declared) was assessed with the question "Have you ever had asthma?" while asthma symptoms were identified with the question "Have you had wheezing or whistling in your chest at any time in the last 12 months?"

A total of $25.7 \%$ of the respondents $(n=4783)$ were recruited in a randomised procedure to participate in a complementary clinical assessment, of whom $27.8 \%$ were aged $6-7$ years $(n=1329), 27.6 \%$ were aged $13-14$ years $(n=1321)$ and $44.6 \%$ were adults $(n=2133)$. Clinical assessment included medical history, physical examination and spirometry with bronchodilator challenge. Sensitisation was confirmed by a positive skin prick test (SPT) for airborne allergens where the response was recorded according to applicable standards. A wheal diameter of at least $3 \mathrm{~mm}$ was considered a positive reaction according to the EAACI recommendation $[19,20]$. Serum specific IgE (slgE) to Dermatophagoides pteronyssinus (d1), Timothy grass (g6), Alternaria alternata (m6), and cat (e1) was assayed using the reference method CAP (Phadia reagents, UniCAP 100 Laboratory System) $(n=$ 4077 records with slgE). The concentration of slgE antibodies of at least $0.70 \mathrm{lU} / \mathrm{ml}$ (classes 2-6) was considered positive. The diagnoses were verified based on the ARIA [21, 22] and GINA criteria [23, 24].

Statistical analyses used a test for equality of proportions (prop.test) to compare the prevalence of individual allergic conditions. Odds ratios (OR) with their 95\% con- fidence intervals $(\mathrm{Cl})$ were calculated for each potential risk factor, individual diagnosis, and age group. The $\mathrm{R}$ software package was used for the analyses (www.rproject.org)

In the questionnaire, allergic rhinitis was declared by $22.6 \%(n=4,192)$ of the respondents $(23.54 \%$ of the 6-7-year-olds, $24.6 \%$ of the $13-14$-year-olds and $21.0 \%$ of the adults). Clinically, AR was diagnosed in $28.9 \%$ ( $n=1,385)$ of the subjects, with $47.7 \%$ suffering from intermittent allergic rhinitis and $52.3 \%$ suffering from persistent allergic rhinitis [25]. Asthma was declared in the questionnaire by $4.6 \%(n=860)$ of the respondents. The presence of whistling or wheezing was reported by $13.5 \%(n=2,508)$ of the subjects. A clinical diagnosis of asthma was made in $10.6 \%(n=505)$ of the subjects, and allergic asthma was diagnosed in 6.5\% $(n=313)$ [26]. This diagnosis was most common among the 13-14-yearolds, at $7.6 \%(n=100)$. The differences in prevalence of allergic asthma between the three age groups were not statistically significant.

The study was approved by the relevant institutional Bioethics Committee. It was carried out as part of the project "Implementation of the system for prevention and early diagnosis of allergic disorders in Poland" (No. 6 P05 2005 C/06572) funded by the Ministry for Health and Ministry for Science in Warsaw, Poland.

\section{Results}

\section{Prevalence of allergic sensitisation}

Of the 4,783 participants who underwent skin prick testing for airborne allergens (SPT), 45.8\% tested positive for at least one allergen. Positive SPT results were noted significantly more frequently among males (49.3\%) than females $(42.9 \%)(p<0.05)$. Positive results were least common (39.3\%) among the 6-7-year-old children $(n=1329)$. They were significantly more common among the 13-14-year-old adolescents $(48.6 \%, n=1321)$ and the adults $(48.2 \%, n=2133)$.

Regarding the entire study population, positive SPT results most commonly revealed sensitisation to Dermatophagoides pteronyssinus allergens (23.4\%). Dermatophagoides pteronyssinus allergy was also most common in each of the three age groups; however, this rate was significantly lower among the 6-7-year-olds (16.2\%) than among the 13-14-year-olds (27.5\%) and the adults $(25.4 \%)(p<0.05)$ (Figure $1 \mathrm{~A})$. The estimated prevalence of sensitisation to $D$. pteronyssinus antigens based on a combination of SPT and SlgE assays for the entire study population was similar (23.7\%), and the rates for the three age groups were also significantly lower in the 6-7-year-old group (17.4\%) compared to the 13-14-yearolds (27.1\%) and the adults (25.1\%) (Figure $1 \mathrm{~B}$ ).

The second most commonly sensitising antigen in the entire group was grass pollen allergen (21.3\%). The sensitisation rate for this antigen was significant- 
A

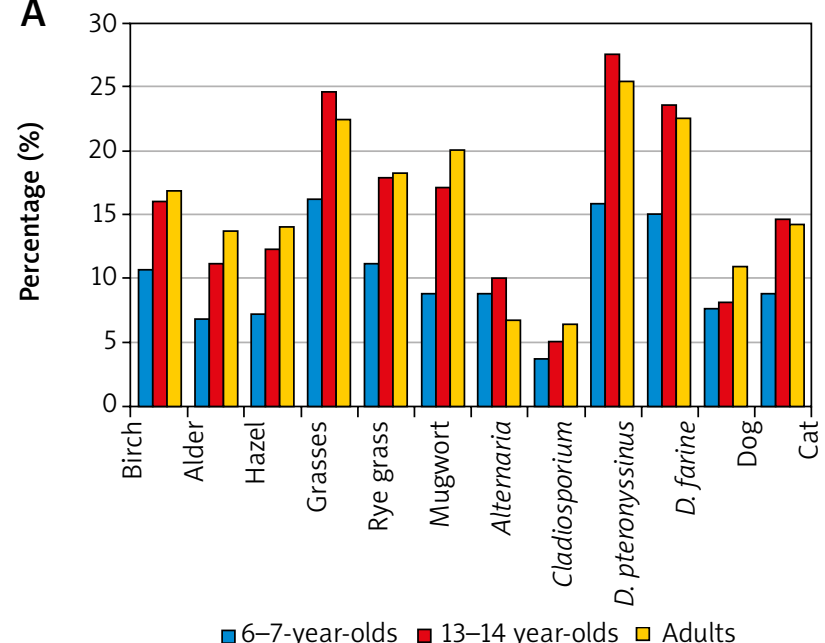

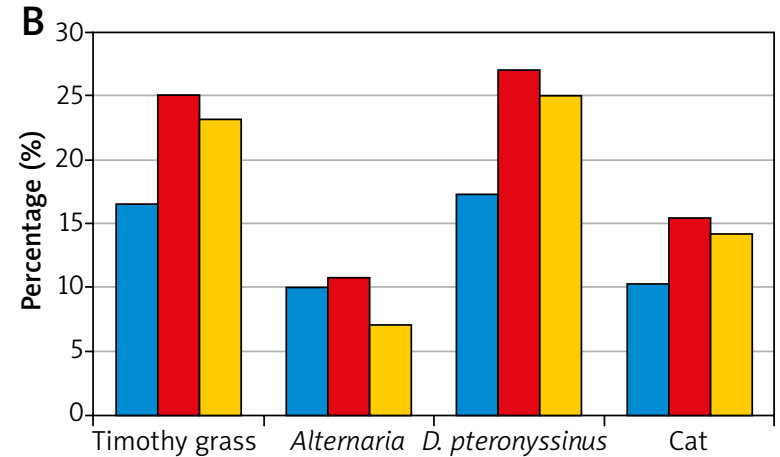

口6-7-year-olds $\square$ 13-14 year-olds $\square$ Adults

Figure 1. Prevalence of sensitisation to airborne allergens by age group as assessed by skin prick testing (SPT) alone $(n=4783)(\mathrm{A})$ and the combination of SPT and an slgE assay $(n=4077)(\mathrm{B})$

ly lower among the 6-7-year-olds (15.9\%) compared to the 13-14-year-olds (24.6\%) and the adults (22.5\%) $(p<0.05)$. The prevalence of sensitisation to grass pollen antigens assessed by combining the SPT and serum slgE results was $22 \%$ for the entire group examined and was also significantly lower in the 6-7-year olds (16.6\%) than among the 13-14-year-olds (25.1\%) and the adults (23.1\%) $(p<0.05)$ (Figure $1 \mathrm{~B})$.

The allergen of Dermatophagoides farinae was the third most common sensitising antigen according to SPT results, both for the entire study group (20.7\%) and in individual age groups. The sensitisation rates for this allergen were significantly lower among the 6-7-year-olds (14.9\%) compared to the 13-14-year-olds (23.6\%) and the adults $(22.5 \%)(p<0.05)$ (Figure $1 \mathrm{~A})$.

Rye, classified in the grass family, also caused less sensitisation among the 6-7-year-olds (11.2\%) than among the $13-14$-year-olds (17.9\%) and the adults (18.3\%) $(p<0.05)$. Among other seasonal allergens, sensitisation to birch, the most potent allergen among trees, was revealed by SPT testing among the 6-7-year-olds more often $(10.7 \%)$ than sensitisation to the weed Artemisia (8.8\%). This ratio was reversed and the rates were almost twice as high among the 13-14-year-olds and adults, with positive SPT results to the birch allergen noted in 16.1\% and $16.8 \%$, respectively, and to Artemisia in $17.2 \%$ and $20.1 \%$, respectively (Figure $1 \mathrm{~A}$ ).

Among animal-derived allergens, there was greater sensitisation to feline allergen than canine allergen across all groups, with the 6-7-year-olds demonstrating the lowest rates. The rates of feline allergen sensitisation in the adults assessed by combining SPT and slgE results vs. SPT alone were the same, at $14.2 \%$, while in the two younger groups the rates diagnosed by combining SPT and slgE assays were slightly higher than those assessed with SPT only, with rates of $10.2 \%$ vs. $8.8 \%$, respectively, among the $6-7$-year-olds and $15.4 \%$ vs. $14.7 \%$ among the 13-14-year-olds (Figure 1).

Among mould allergens, Alternaria produced more sensitisation than Cladosporium across all age groups. Among the 13-14-year-olds and adults, the prevalence of sensitisation to Alternaria allergens diagnosed by SPT and SIgE vs. SPT alone was similar, at $10.7 \%$ vs. $10.1 \%$ in the younger group and $7.1 \%$ vs. $6.8 \%$ in the older group, while in the 6-7-year-olds, the rate based on SPT and slgE was higher by $1.2 \%$ (10.0\%) than the rate based on SPT alone (8.8\%) (Figure 1).

\section{Allergic sensitisation in relation to allergic rhinitis}

Clinically diagnosed AR was very strongly associated with sensitisation to house dust mite allergens across all age groups. While the rates of $D$. pteronyssinus sensitisation assessed by SPT alone were similar in all age groups, with the odds ratios ranging from $6.70(95 \% \mathrm{Cl}$ : 4.9-9.2) among the 6-7-year-olds to 7.25 (95\% Cl: 5.59.5) and 7.33 (95\% Cl: 5.9-9.1) among the 13-14-yearolds and adults, respectively, the rates of sensitisation to $D$. pteronyssinus antigens diagnosed by a combination of SPT and an slgE assay indicated a substantial intensification of the association between sensitisation and AR among the 6-7- and 13-14-year-olds to OR $=10.10$ (95\% Cl: 7.24-14.21) and OR = 10.29 (95\% Cl: 7.5014.22), respectively. This association was the strongest compared to sensitisation rates to other airborne allergens. Sensitisation to D. pteronyssinus allergens was most strongly associated with persistent AR across all age groups. The highest odds ratio of 16.01 (95\% Cl: 10.71-24.39) was recorded among the 6-7-year-olds as assessed by combined SPT and slgE positivity, compared to $\mathrm{OR}=13.30$ (95\% Cl: 9.27-19.31) among the 13-14-year- 
olds and $\mathrm{OR}=9.84(95 \% \mathrm{Cl}: 7.45-13.09)$ among the adults (Table 1 ).

Sensitisation to pollen antigens was also a major risk factor for AR across all age groups. When assessed on the basis of combined SPT and SIgE positivity, this association was most marked among the adults ( $O R=$ 9.16, 95\% Cl: 7.18-11.75), in whom grass pollen allergen sensitisation increased the risk of both intermittent and persistent AR to a similar extent, while in both younger groups the risk of subjects sensitised to grass pollen allergens developing intermittent AR was nearly twice as high as the risk of development of persistent AR (Table 1).

All age groups also registered a marked association between AR, mainly persistent, and sensitisation to animal-derived airborne allergens, being the highest for feline allergens as assessed by SPT combined with slgE, with the associated odds ratios ranging from 8.61 (95\% Cl: 5.75-13.11) among the 6-7-year-olds to 6.06 (95\% Cl: 4.25-8.73) among the 13-14-year-olds (Table 1).

\section{Allergic sensitisation in relation to asthma}

The prevalence of declared asthma and asthma symptoms in the questionnaire increased most strongly in association with sensitisation to $D$. pteronyssinus as diagnosed by means of SPT combined with slgE. The rise was similar in all age groups (Figure 2). Sensitisation to the house dust mite was the strongest risk factor for clinically diagnosed allergic asthma in the 6-7-year-old age group both when the diagnosis was based on SPT alone (OR = 8.2, 95\% Cl: 5.1-13.2) (Table 2) and when SPT was combined with slgE $(\mathrm{OR}=8.34,95 \% \mathrm{Cl}$ : 4.45-16.32) (Figure 2).

Among the other perennial allergens, sensitisation to animal-derived allergens, especially feline, was more strongly associated with both questionnaire-declared and clinically diagnosed allergic asthma than sensitisation to Alternaria allergens across all age groups (Table 2, Figure 2).

Among seasonal allergens, clinically diagnosed allergic asthma was markedly associated with sensitisation to grass pollen allergens. That association was similarly strong across all age groups (Figure 2, Table 2). Also a marked association between sensitisation to a seasonal allergen and clinical diagnosis of allergic asthma existed for birch pollen, with odds ratios ranging from 4.7 (95\% Cl: 2.8-7.8) among the 6-7-year-olds to 3.5 (95\% Cl: 2.3-5.4) among the 13-14-year-olds (Table 2).

In all age groups, the increase of the percentage of allergic rhinitis was observed with an increasing number of sensitising allergens, from 1 out of 4 to 3 out of 4 allergens, i.e. in polysensitised individuals (Figure 3).

\section{Allergic rhinitis in relation to asthma}

The odds ratio analysis revealed an association between questionnaire-declared asthma and asthma symptoms and the diagnosis of AR across all age groups, with odds ratio values ranging from 6.2 (95\% Cl: 4.8-7.9) among the 13-14-year-olds to 4.3 (95\% Cl: $3.2-5.8)$ in the youngest age group for declared asthma and from 4.3 (95\% Cl: 3.5-5.2) among the 13-14-year-olds to 3.1 (95\% Cl: 2.7-3.5) among the adults for questionnairedeclared symptoms of asthma.

Clinically, AR was found to be the strongest risk factor for allergic asthma in the youngest age group. A diagnosis of AR increased the risk of being diagnosed with allergic asthma from an OR of 13.44 (95\% Cl: 7.3-26.2) among the 6-year-olds to OR 7.92 (95\% Cl: 4.6-14.1) among the 13-14-year-olds. A diagnosis of persistent AR increased the risk of having clinically diagnosed allergic asthma to a much greater extent than a diagnosis of intermittent AR across all age groups (Table 3 ).

\section{Discussion}

The prevalence of sensitisation to allergens varies between different geographical regions and affects up to $50 \%$ of the population [27]. The percentage of $45.8 \%$ positive skin prick test results for at least one allergen places the study population in the highly sensitised group. We found the highest sensitisation rates to allergens of the house dust mite $D$. pteronyssinus and, among seasonal allergens, to grass pollen. House dust mites have been recognized as a dominant allergen throughout different parts of the world; the prevalence of sensitisation to D. pteronyssinus was significantly higher than the study median in sites in Belgium, France, the Netherlands, the UK, Ireland, New Zealand and in Australia. However, it was low in Scandinavia, Spain, Iceland and Italy [27]. In Nordic countries it is the cat and dog, together with pollen, that are the dominant sensitisers $[14,28]$.

The prevalence of SPT positivity in our study was significantly lower among 6-7-year-old children compared to 13-14-year-olds and adults, including the most common sensitisers of D. pteronyssinus and grass pollen. These findings are in accordance with ISAAC Phase Three Study Group data, where the average prevalence (across all centres that participated in Phase Three) of current rhinoconjunctivitis symptoms for the 13-14-year-olds was 1.7-fold higher than for the 6-7-year-olds [1].

In our study, sensitisation to any allergen was significantly associated with AR in all age groups. Clinically diagnosed AR was very strongly associated with allergy to the antigens of the house dust mite $D$. pteronyssinus across all age groups, the association being up to twice as strong in the younger age groups as compared with the adults. The strongest association with sensitisation to $D$. pteronyssinus allergens was that of persistent $A R$, the strength of the association growing inversely proportionally to age. Across all age groups, AR, mainly the persistent form, was also very markedly associated with sensitisation to feline allergens (odds ratio analysis). Sen- 


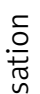

ज्ञ

ญे วิ

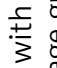

穻合

능

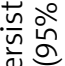

$\stackrel{n}{\infty} \frac{n}{\pi}$

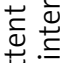

है

논

훈

충ㅇํํ

응

衣

ज

은

츰음

毫

ठ

品 है

苧

究

듬 $\frac{\bar{\sigma}}{\sigma}$

.

을ํㄹ

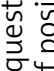

0
0

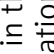

밈

웜

जी

产占

वे

总高

돈

.

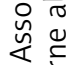

繁旁

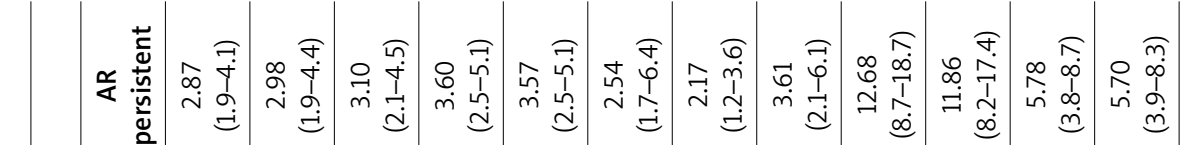

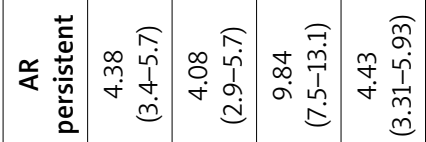

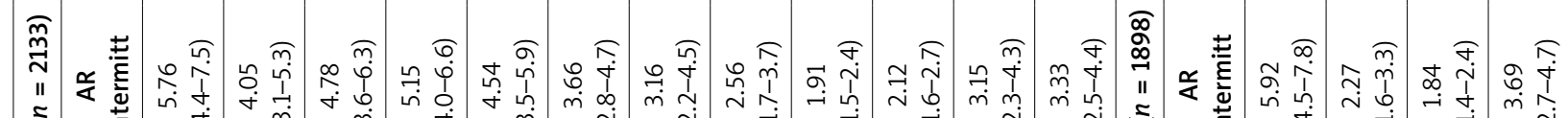

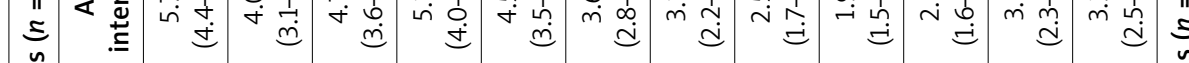

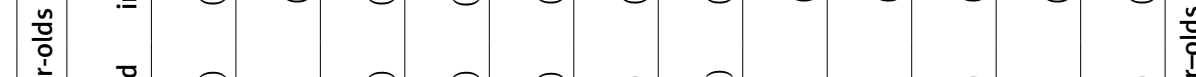

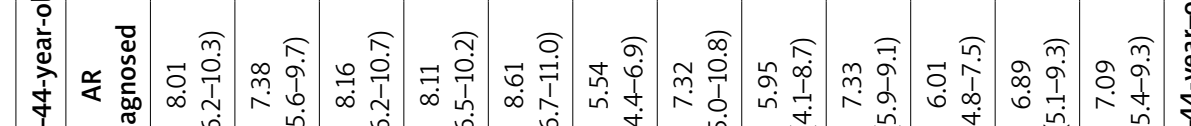

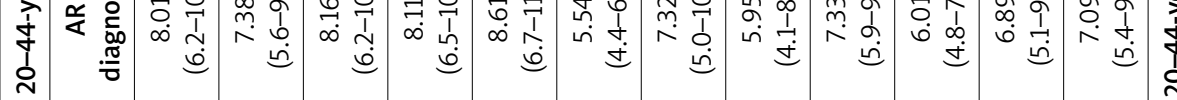

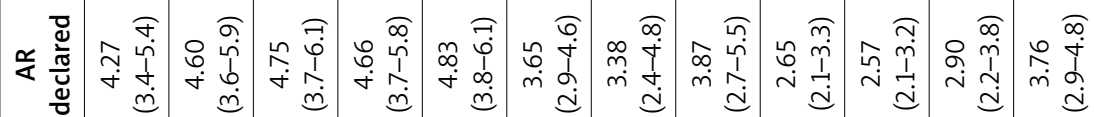

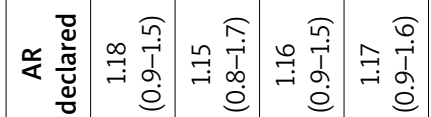

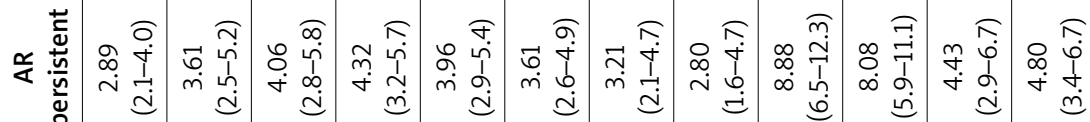

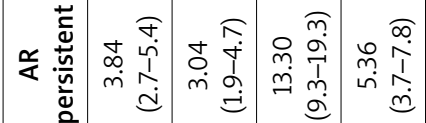

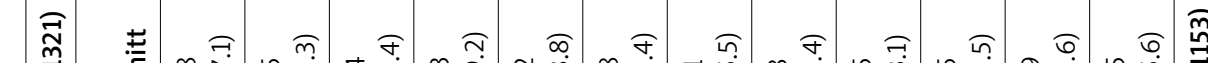

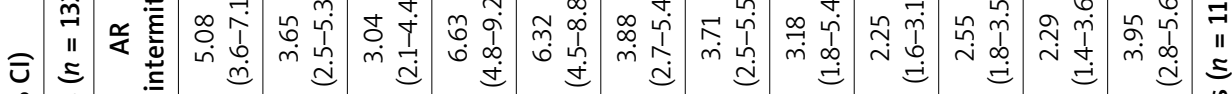
ㅇํㅇ ำ

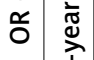

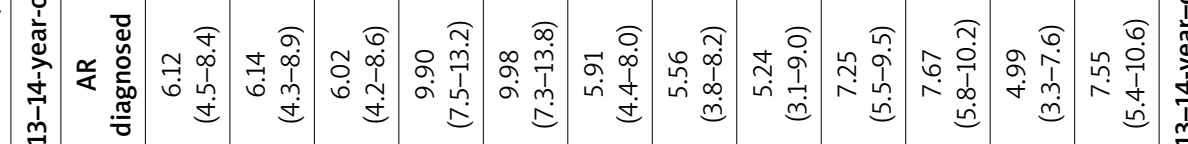

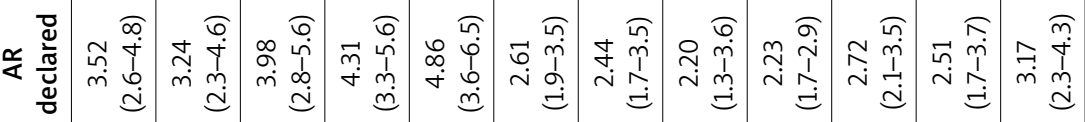

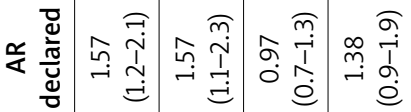

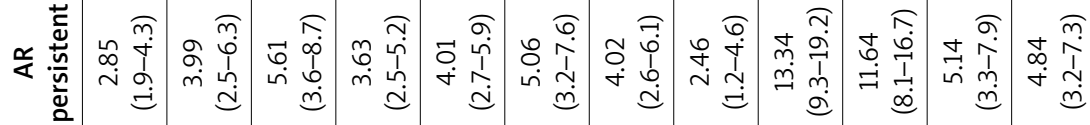

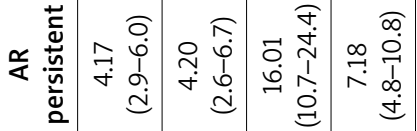

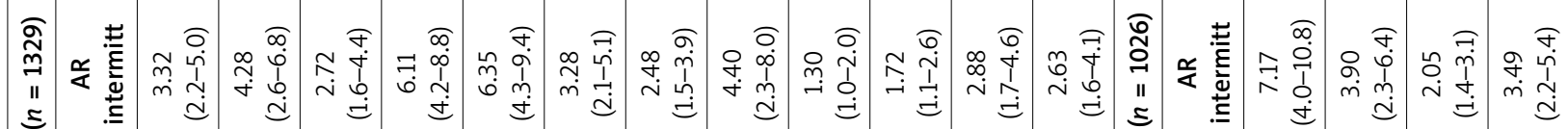
n

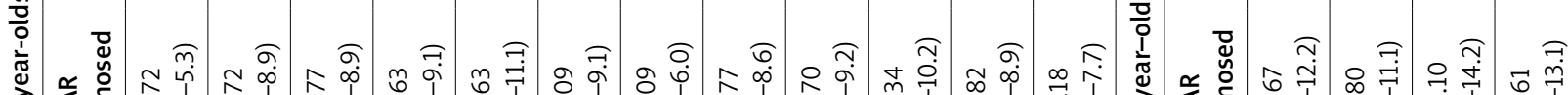

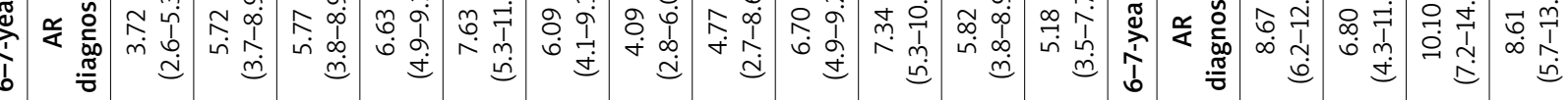

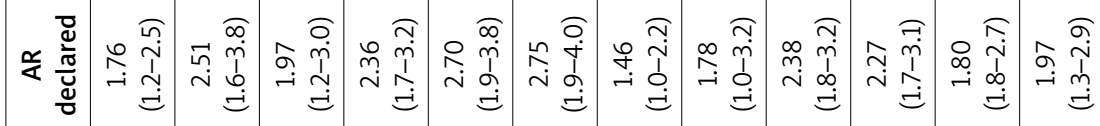

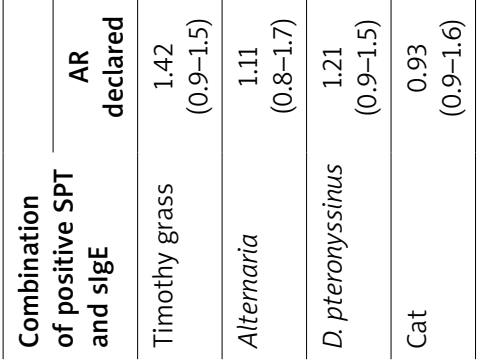



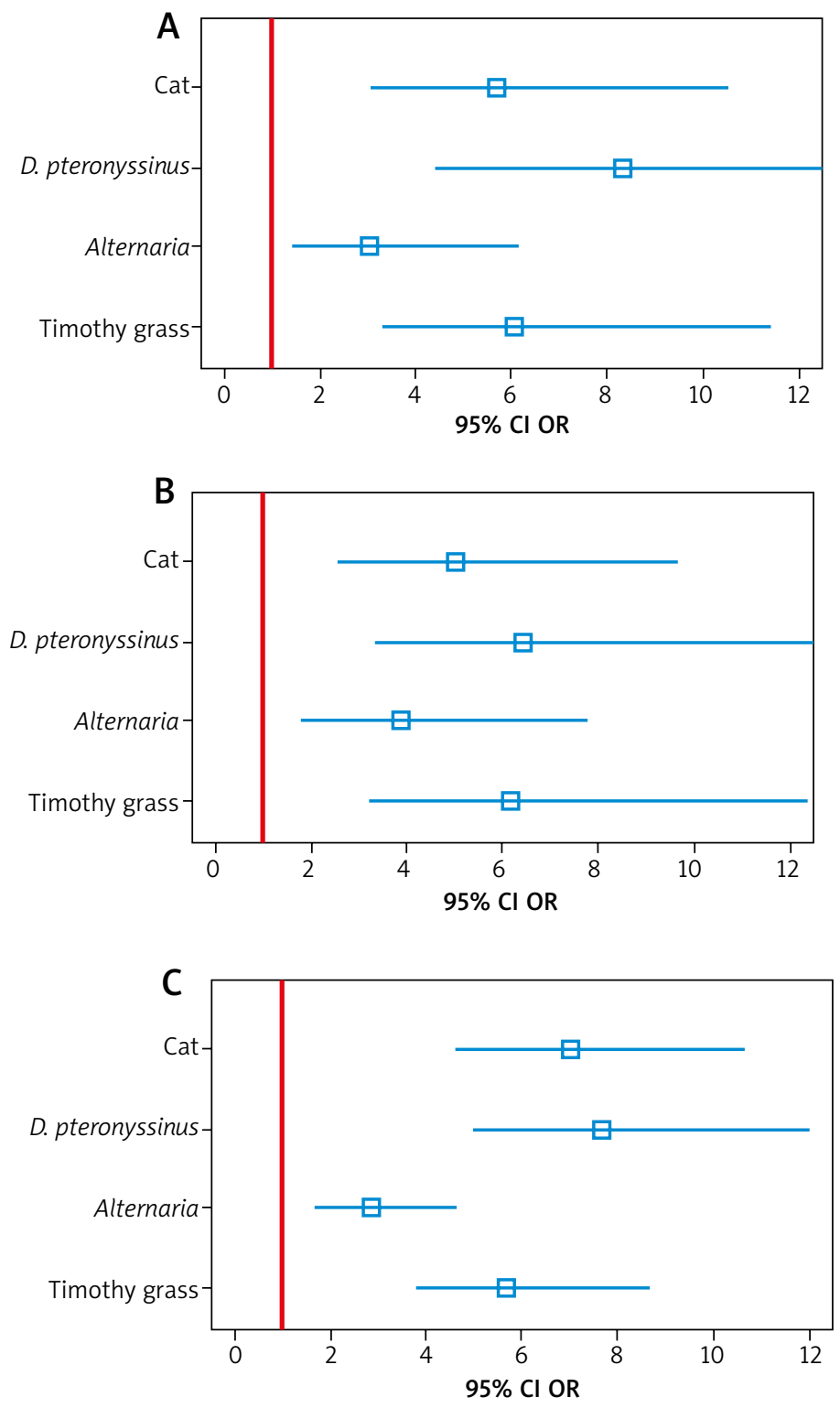

Figure 2. Associations between allergic asthma diagnosed clinically and sensitisation to airborne allergens (assessed by combined SPT and slgE positivity), measured as odds ratios (OR) with $95 \%$ confidence intervals $(95 \% \mathrm{Cl})$ by age group (6-7-year-olds (A), 13-14 year-olds (B), adults (C))

sitisation to grass pollen allergens was another strong risk factor for AR in the study population.

The above findings are consistent with data from many other authors. According to Bousquet et al., mites and pollen are the major allergens associated with allergic rhinitis $[29,30]$. Lam et al. found mite sensitisation a strong predictor of rhinitis [12]. Sensitisation to pollen has been strongly associated with rhinitis according to many studies $[9,17,20$, 29-32] but not many have analysed sensitisation to pollen as a risk factor for rhinitis in different age groups. Warm et al. studied a population of adult Swedes aged 21-86 years to find that sensitisation to Timothy grass pollen, birch, and cat was significantly associated with allergic rhinitis and that the strength of the association decreased with age [5].

Schoefer et al. in a study of adult Germans found, as we and the studies quoted above have, a clear association of sensitisation to outdoor (grass and birch pollen) and cat allergens with the development of hay fever; however, they found a significantly increased risk of doctor-diagnosed asthma for individuals sensitised to indoor allergens (house dust mites and also cat) [33]. Stoltz et al. also believe that while detectable levels of slgE to seasonal allergens are associated with an increased rhinitis risk, increased levels of slgE to perennial allergens are associated with an increased risk of asthma [34].

Sensitisation to any allergen was strongly associated with asthma in all age groups of our study. Sensitisation to house dust mites emerged as the strongest risk factor for clinically diagnosed allergic asthma. Among perennial allergens, feline allergy was markedly associated both with questionnaire-declared asthma and clinically diagnosed allergic asthma.

In accordance with a number of previous studies in adults and children [3, 10, 32, 35] the current study demonstrated that sensitisation to indoor allergens was strongly associated with asthma. Simpson et al. in a multivariate regression analysis performed as part of the Manchester Asthma and Allergy Study found that sensitisation to house dust mite, cat, dog and grasses were all independently associated with asthma [32].

Across all age groups in our study, a clinical diagnosis of allergic asthma was also strongly associated with sensitisation to grass pollen allergens. Unlike our study, the Manchester Asthma and Allergy Study found that sensitisation to grass pollen allergens appeared to be of much less importance in asthma than sensitisation to indoor allergens [32]. One hypothesis advanced to account for the finding that pollen allergens were more often associated with rhinitis highlighted that pollen particles are generally too large to penetrate the lower respiratory tract. However, it has been shown that pollen grains can be found in bronchial secretions and lung parenchyma [36]. What is more, allergen-containing pollen starch granules released from the pollen grains can easily enter the lower respiratory tract and trigger inflammation there [37], a fact that can lend support to our findings.

In summary, in our study, allergic sensitisation to airborne allergens was significantly associated with asthma and even more strongly with allergic rhinitis. These results are consistent with data from studies of numerous populations $[5,12,14,33,38]$. It may be due to the fact that rhinitis has been mainly associated with allergic sensitisation, whereas asthma is also associated with several environmental factors including smoking, traffic exhausts, socioeconomic status, early respiratory infections, living in damp houses, environmental conditions, paracetamol usage and obesity [38].

In the study population, the percentage of allergic rhinitis increased with the number of sensitising allergens across all age groups, suggesting a positive association be- 
Table 2. Association between questionnaire-declared asthma/clinically diagnosed allergic asthma and sensitisation to airborne allergens (positive SPT) measured as odds ratios (OR) with 95\% confidence intervals ( $95 \% \mathrm{Cl}$ ) for individual age groups

\begin{tabular}{|c|c|c|c|c|c|c|}
\hline \multirow[t]{3}{*}{ Allergen } & \multicolumn{6}{|c|}{ OR $(95 \% \mathrm{Cl})$} \\
\hline & \multicolumn{2}{|c|}{$6-7$-year-olds $(n=1329)$} & \multicolumn{2}{|c|}{ 13-14-year-olds $(n=1321)$} & \multicolumn{2}{|c|}{ 20-44-year-olds $(n=2133)$} \\
\hline & Asthma declared & Allergic asthma & Asthma declared & Allergic asthma & Asthma declared & Allergic asthma \\
\hline Birch & $\begin{array}{c}2.2 \\
(1.2-4.2)\end{array}$ & $\begin{array}{c}4.7 \\
(2.8-7.8)\end{array}$ & $\begin{array}{c}1.7 \\
(1.0-2.7)\end{array}$ & $\begin{array}{c}3.5 \\
(2.3-5.4) \\
\end{array}$ & $\begin{array}{c}2.6 \\
(1.7-3.9)\end{array}$ & $\begin{array}{c}4.2 \\
(2.9-6.0)\end{array}$ \\
\hline Alder & $\begin{array}{c}2.4 \\
(1.1-4.9) \\
\end{array}$ & $\begin{array}{c}5.4 \\
(3.0-9.5) \\
\end{array}$ & $\begin{array}{c}1.5 \\
(0.8-2.6) \\
\end{array}$ & $\begin{array}{c}5.0 \\
(3.2-7.9) \\
\end{array}$ & $\begin{array}{c}2.3 \\
(1.5-3.6) \\
\end{array}$ & $\begin{array}{c}4.1 \\
(2.8-5.9) \\
\end{array}$ \\
\hline Hazel & $\begin{array}{c}2.2 \\
(1.1-4.6)\end{array}$ & $\begin{array}{c}7.4 \\
(4.3-12.7)\end{array}$ & $\begin{array}{c}1.7 \\
(1.0-2.9)\end{array}$ & $\begin{array}{c}6.6 \\
(4.3-10.3)\end{array}$ & $\begin{array}{c}2.6 \\
(1.7-4.0)\end{array}$ & $\begin{array}{c}4.9 \\
(3.4-7.1)\end{array}$ \\
\hline Grasses & $\begin{array}{c}2.3 \\
(1.3-4.0)\end{array}$ & $\begin{array}{c}5.5 \\
(3.5-8.9)\end{array}$ & $\begin{array}{c}2.3 \\
(1.5-3.5)\end{array}$ & $\begin{array}{c}6.5 \\
(4.3-10.3)\end{array}$ & $\begin{array}{c}3.8 \\
(2.6-5.6)\end{array}$ & $\begin{array}{c}6.3 \\
(4.4-9.1)\end{array}$ \\
\hline Rye grass & $\begin{array}{c}2.1 \\
(1.1-4.0) \\
\end{array}$ & $\begin{array}{c}6.1 \\
(3.7-10.0) \\
\end{array}$ & $\begin{array}{c}2.8 \\
(1.8-4.4) \\
\end{array}$ & $\begin{array}{c}6.1 \\
(4.0-9.3) \\
\end{array}$ & $\begin{array}{c}2.6 \\
(1.7-3.9) \\
\end{array}$ & $\begin{array}{c}6.1 \\
(4.3-8.8) \\
\end{array}$ \\
\hline Mugwort & $\begin{array}{c}2.0 \\
(1.0-4.1)\end{array}$ & $\begin{array}{c}4.9 \\
(2.9-8.3)\end{array}$ & $\begin{array}{c}2.0 \\
(1.2-3.1)\end{array}$ & $\begin{array}{c}3.9 \\
(2.5-5.9)\end{array}$ & $\begin{array}{c}2.3 \\
(1.5-3.5)\end{array}$ & $\begin{array}{c}4.6 \\
(3.2-6.5)\end{array}$ \\
\hline Alternaria & $\begin{array}{c}1.3 \\
(0.6-2.9)\end{array}$ & $\begin{array}{c}3.6 \\
(2.0-6.3)\end{array}$ & $\begin{array}{c}2.0 \\
(1.2-3.5)\end{array}$ & $\begin{array}{c}3.0 \\
(1.8-5.0)\end{array}$ & $\begin{array}{c}2.3 \\
(1.3-4.1)\end{array}$ & $\begin{array}{c}4.4 \\
(2.8-7.0)\end{array}$ \\
\hline Cladosporium & $\begin{array}{c}2.3 \\
(0.9-6.0) \\
\end{array}$ & $\begin{array}{c}3.3 \\
(1.5-7.3) \\
\end{array}$ & $\begin{array}{c}2.0 \\
(1.0-4.2) \\
\end{array}$ & $\begin{array}{c}3.2 \\
(1.7-5.2) \\
\end{array}$ & $\begin{array}{c}1.5 \\
(0.8-3.0) \\
\end{array}$ & $\begin{array}{c}4.5 \\
(2.9-7.2) \\
\end{array}$ \\
\hline D. pteronyssinus & $\begin{array}{c}3.0 \\
(1.7-6.1)\end{array}$ & $\begin{array}{c}8.2 \\
(5.1-13.2)\end{array}$ & $\begin{array}{c}1.7 \\
(1.1-2.7) \\
\end{array}$ & $\begin{array}{c}6.6 \\
(4.3-10.3) \\
\end{array}$ & $\begin{array}{c}3.3 \\
(2.2-4.8) \\
\end{array}$ & $\begin{array}{c}6.9 \\
(4.8-10.1) \\
\end{array}$ \\
\hline D. farinae & $\begin{array}{c}4.7 \\
(2.8-7.9)\end{array}$ & $\begin{array}{c}7.5 \\
(4.6-12.1)\end{array}$ & $\begin{array}{c}2.2 \\
(1.4-3.4)\end{array}$ & $\begin{array}{c}9.4 \\
(6.0-14.8)\end{array}$ & $\begin{array}{c}3.6 \\
(2.5-5.4)\end{array}$ & $\begin{array}{c}6.8 \\
(4.7-9.8)\end{array}$ \\
\hline Dog & $\begin{array}{c}3.4 \\
(1.8-6.5) \\
\end{array}$ & $\begin{array}{c}5.9 \\
(3.4-9.9) \\
\end{array}$ & $\begin{array}{c}3.1 \\
(1.8-5.3) \\
\end{array}$ & $\begin{array}{c}5.5 \\
(3.4-9.1) \\
\end{array}$ & $\begin{array}{c}2.9 \\
(1.8-4.6) \\
\end{array}$ & $\begin{array}{c}4.4 \\
(3.0-6.5) \\
\end{array}$ \\
\hline Cat & $\begin{array}{c}3.8 \\
(2.1-7.0)\end{array}$ & $\begin{array}{c}7.0 \\
(4.2-11.7)\end{array}$ & $\begin{array}{c}2.6 \\
(1.6-4.1)\end{array}$ & $\begin{array}{c}5.6 \\
(3.7-8.6)\end{array}$ & $\begin{array}{c}6.1 \\
(4.1-9.0)\end{array}$ & $\begin{array}{c}9.2 \\
(6.4-13.3)\end{array}$ \\
\hline
\end{tabular}

tween the degree of sensitisation (assessed by the number of positive skin tests and/or slgE) and the disease. This observation is consistent with data from other authors in various regions of the world reporting that sensitisation to multiple allergens was associated with a high prevalence of respiratory allergy [8, 12, 14, 39-41].

Clinically diagnosed AR was found to be the strongest risk factor for allergic asthma in the youngest age group. A diagnosis of AR increased the risk of a diagnosis of allergic asthma with an odds ratio of 16 in the 6-7-year-old age group and with an odds ratio of 8 among the 13-14-yearolds and among adults. A diagnosis of persistent AR increased the risk of being diagnosed with allergic asthma to a much greater degree than a diagnosis of intermittent AR. Data from numerous papers, confirmed by the position of ARIA, confirm that rhinitis increases the risk of asthma [11, 22, 42]. Moreover, asthma prevalence increases with the duration of rhinitis [22, 29]. The ECRHS study confirmed persistent rhinitis as a major risk factor for asthma, with odds ratios of 11 for the atopic and 17 for the non-atopic phenotype [11]. The concept of "united airway disease" has introduced an integrated view of rhinitis and asthma $[22,36,43]$. Accordingly, ARIA guidelines recommend that patients with persistent rhinitis should be evaluated for asthma while GINA guidelines advise the evaluation of asthmatic patients for nasal involvement [23, 24].

The strengths of our study are the enrolment of a large population-based sample covering children, adolescents and adults and the methodology employed to determine the presence of allergic sensitisation. Skin prick testing is commonly used for this purpose in epidemiologic studies. However, while skin prick tests seem to be more sensitive, the slgE test is more specific [2]. The use of slgE antibody testing in addition to skin prick testing increased the accuracy of the diagnosis [44-46].

Our study has some limitations. One of the problems of a two-phase design is the proportion of participants willing to undertake the second phase. Adults were less numerously represented than 6-7-year-olds or 13-14-yearolds in the clinical assessment phase as compared to the questionnaire phase. Univariate risk analyses failed to detect the influence of other variables.

The outcomes of our study are of practical relevance. Familiarity with risk factors of allergic respiratory disease relevant for a given population is very helpful for an appropriate diagnostic and preventive approach. 

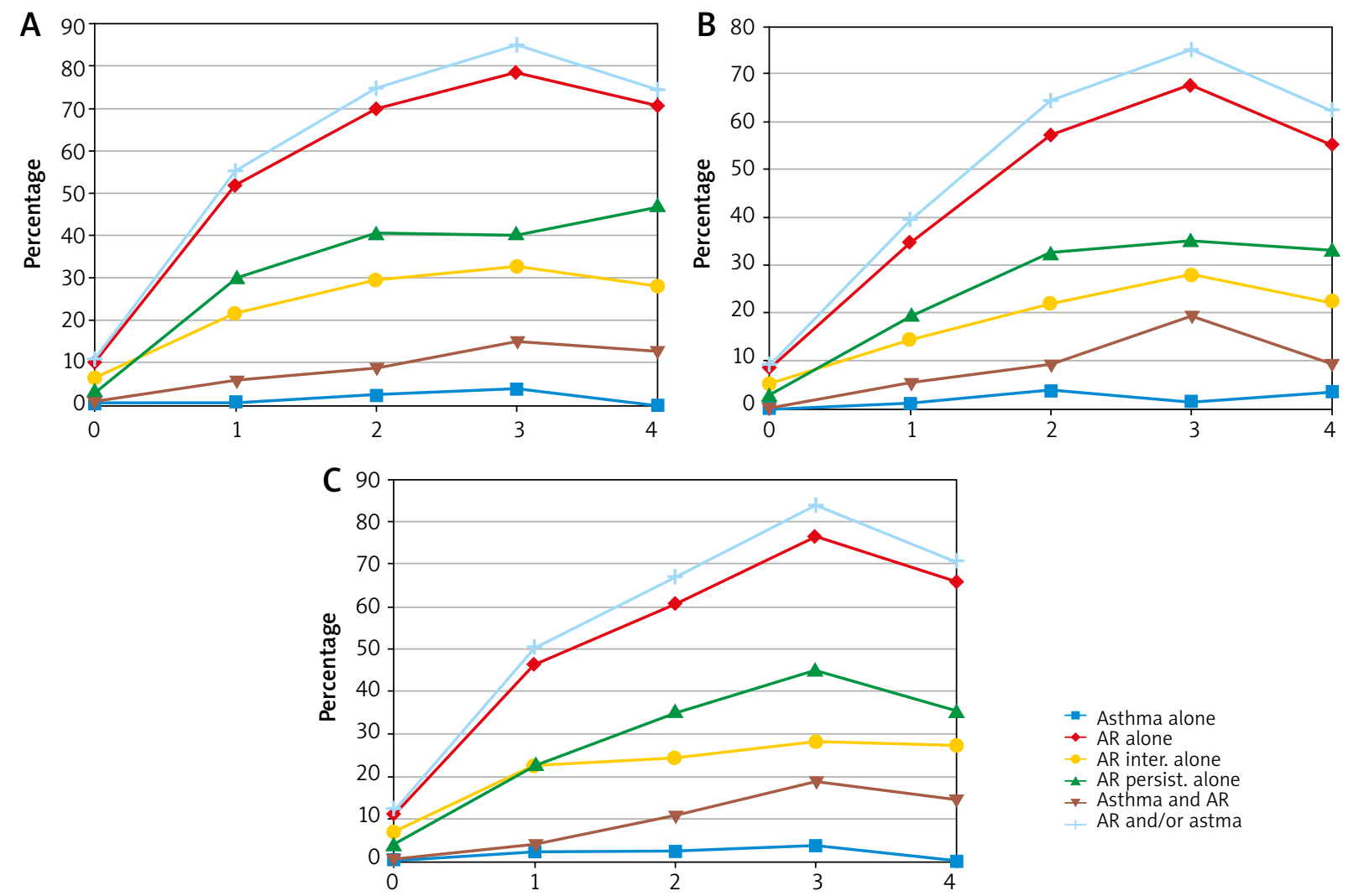

Figure 3. Percentage of airborne allergic diseases by number of sensitising allergens (assessed by combined SPT and slgE positivity) in individual age groups $(n=4077)(6-7$-year-olds $(\mathbf{A}), 13-14$ year-olds (B), adults (C))

Table 3. Association between clinically diagnosed allergic asthma and allergic rhinitis as measured by odds ratios (OR) with $95 \%$ confidence intervals $(95 \% \mathrm{Cl})$ in individual age groups

\begin{tabular}{lccc}
\hline AR & \multicolumn{3}{c}{ OR (95\% Cl) } \\
\cline { 2 - 4 } & $\begin{array}{c}\text { 6-7-year-olds } \\
(n=1329)\end{array}$ & $\begin{array}{c}\text { 13-14-year-olds } \\
(n=1321)\end{array}$ & $\begin{array}{c}20-44-y e a r-o l d s \\
(n=2133)\end{array}$ \\
\cline { 2 - 4 } & \multicolumn{3}{c}{ Allergic asthma } \\
\hline AR & 13.44 & 7.92 & 8.10 \\
& $(7.3-26.2)$ & $(4.6-14.1)$ & $(5.1-13.3)$ \\
\hline AR & 3.35 & 1.63 & 2.24 \\
intermittent & $(1.8-5.9)$ & $(0.9-2.9)$ & $(1.4-3.5)$ \\
\hline AR & 9.14 & 7.42 & 6.02 \\
persistent & $(5.3-15.7)$ & $(4.5-12.2)$ & $(3.9-9.2)$ \\
\hline
\end{tabular}

\section{Conclusions}

Sensitisation to airborne allergens was significantly associated with asthma and even more strongly with allergic rhinitis across all age groups. Allergic rhinitis and asthma share common risk factors; independently of age, the strongest associations were observed for sensitisation to allergens from D. pteronyssinus, D. farinae, grass pollen and cats. AR was the strongest risk factor for allergic asthma in the youngest group. Persistent AR increased asthma risk more than intermittent $A R$ in all age groups.

\section{Conflict of interest}

The authors declare no conflict of interest.

\section{References}

1. At-Khaled N, Pearce N, Anderson HR, et al.; the ISAAC Phase Three Study Group. Global map of the prevalence of symptoms of rhinoconjunctivitis in children: The International Study of Asthma and Allergies in Childhood (ISAAC) Phase Three. Allergy 2009; 64: 123-48.

2. Bousquet J, Castelli C, Daures JP, et al. Assessment of allergen sensitization in a general population-based survey (European Community Respiratory Health Survey I). Ann Epidemiol 2010; 20: 797-803

3. Sunyer J, Jarvis D, Pekkanen J, et al. Geographic variations in the effect of atopy on asthma in the European Community Respiratory Health Study. J Allergy Clin Immunol 2004; 114: 1033-9.

4. Toppila-Salmi S, Huhtala H, Karjalainen J, et al. Sensitization pattern affects the asthma risk in Finnish adult population. Allergy 2015; 70: 1112-20.

5. Warm K, Hedman L, Lindberg A. Allergic sensitization is agedependently associated with rhinitis, but less so with asthma. J Allergy Clin Immunol 2015; 136: 1559-65. 
6. Jaakkola MS, leromnimon A, Jaakkola JJ. Are atopy and specific IgE to mites and molds important for adult asthma? J Allergy Clin Immunol 2006; 117: 642-8.

7. Ziello C, Sparks TH, Estrella N, et al. Changes to airborne pollen counts across Europe. PLoS One 2012; 7: e34076.

8. Burbach GJ, Heinzerling LM, Edenharter G, et al. GA(2)LEN skin test study II: clinical relevance of inhalant allergen sensitizations in Europe. Allergy 2009; 64: 1507-15.

9. Ghunaim N, Wickman M, Almqvist C, et al. Sensitization to different pollens and allergic disease in 4-year-old Swedish children. Clin Exp Allergy 2006; 36: 722-7.

10. Illi S, von Mutius E, Lau S, et al. Perennial allergen sensitisation early in life and chronic asthma in children: a birth cohort study. Lancet 2006; 368: 763-70.

11. Leynaert B, Neukrich C, Kony S, et al. Association between asthma and rhinitis according to atopic sensitization in a populationbased study. J Allergy Clin Immunol 2004; 113: 86-93.

12. Lam HT, Ekerljung L, Bjerg A, et al. Sensitization to airborne allergens among adults and its impact on allergic symptoms: a population survey in northern Vietnam. Clin Transl Allergy 2014; 4: 6.

13. Mallol J, Crane J, von Mutius E, et al. The International Study of Asthma and Allergies in Childhood (ISAAC) phase three: a global synthesis. Allergol Immunopathol (Madr) 2013; 41: 73-85.

14. Pallasaho P, Ronmark E, Haahtela T, et al. Degree and clinical relevance of sensitization to common allergens among adults: a population study in Helsinki, Finland. Clin Exp Allergy 2006; 36: 503-9.

15. Raukas-Kivioja A, Raukas ES, Meren M, et al. Allergic sensitization to common airborne allergens among adults in Estonia. Int Arch Allergy Immunol 2007; 142: 247-54.

16. Simpson A, Tan VY, Winn J, et al. Beyond atopy: multiple patterns of sensitization in relation to asthma in a birth cohort study. Am J Respir Crit Care Med 2010; 181: 1200-6.

17. Shoormasti RS, Fazlollahi MR, Kazemnejad A, et al. IgE sensitization to inhalant allergens and its association with allergic diseases in adults. Iran J Allergy Asthma Immunol 2018; 17: 123-33.

18. Ronmark E, Perzanowski M, Platts-Mills T, et al. Different sensitization profile for asthma, rhinitis, and eczema among 7-8-yearold children: report from the Obstructive Lung Disease in Northern Sweden studies. Pediatr Allergy Immunol 2003; 14: 91-9.

19. Bousquet J, Heinzerling L, Bachert C, et al. Global Allergy and Asthma European Network; Allergic Rhinitis and its Impact on Asthma. Practical guide to skin prick tests in allergy to aeroallergens. Allergy 2012; 67: 18-24

20. Haahtela T, Burbach GJ, Bachert C, et al. Clinical relevance is associated with allergen-specific wheal size in skin prick testing. Clin Exp Allergy 2014; 44: 407-16.

21. Bousquet J, Van Cauwenberge P, Khaltaev N; ARIA Workshop Group; World Health Organization. Allergic rhinitis and its impact on asthma. J Allergy Clin Immunol 2001; 108 (5 Suppl): S147-334.

22. Bousquet J, Khaltaev N, Cruzz AA, et al. Allergic Rhinitis and Its Impact on Asthma (ARIA 2008). Allergy 2008; 68 (Suppl 86): 8-160.

23. National Heart LaBI. Global Initiative for Asthma; Global strategy for asthma management and prevention; Bethesda: National Institutes of Health; 2006.

24. Bousquet J, Clark TJ, Hurd S, et al. GINA guidelines on asthma and beyond. Allergy 2007; 62: 102-12.

25. Samoliński B, Sybilski A, Raciborski F, et al. Prevalence of rhinitis in Polish population according to the ECAP (Epidemiology of Allergic Disorders in Poland) study. Otolaryngol Pol 2009; 63: 324-30.

26. Samoliński B, Sybilski A, Raciborski F, et al. Występowanie astmy oskrzelowej u dzieci, młodzieży i młodych dorosłych w Polsce w świetle badania ECAP. Alergia Astma Immunologia 2009; 14: 27-34.
27. Bousquet J, Chinn S, Janson C, et al. Geographical variation in the prevalence of positive skin tests to environmental aeroallergens in the European Community Respiratory Health Survey I. Allergy 2007; 62: 301-9.

28. Ronmark E, Bjerg A, Perzanowski M, et al. Major increase in allergic sensitization in schoolchildren from 1996 to 2006 in northern Sweden. J Allergy Clin Immunol 2009; 124: 357-63.

29. Bousquet J, Annesi-Maesano I, Carat F, et al. Characteristics of intermittent and persistent allergic rhinitis: DREAMS study group. Clin Exp Allergy 2005; 35: 728-32.

30. Bauchau V, Durham SR. Epidemiological characterization of the intermittent and persistent types of allergic rhinitis. Allergy 2005 ; 60: 350-3.

31. Arshad SH, Tariq SM, Matthews S, Hakim E. Sensitization to common allergens and its association with allergic disorders at age 4 years: a whole population birth cohort study. Pediatrics 2001; 108: E33.

32. Simpson BM, Custovic A, Simpson A, et al. NAC Manchester Asthma and Allergy Study (NACMAAS): risk factors for asthma and allergic disorders in adults. Clin Exp Allergy 2001; 31: 391-9.

33. Schoefer Y, Schafer T, Meisinger C, et al.; KORA Study Group. Predictivity of allergic sensitization (RAST) for the onset of allergic diseases in adults. Allergy 2008; 63: 81-6.

34. Stoltz DJ, Jackson DJ, Evans MD, et al. Specific patterns of allergic sensitization in early childhood and asthma and rhinitis risk. Clin Exp Allergy 2013; 43: 233-41.

35. Gaffin JM, Phipatanakul W. The role of indoor allergens in the development of asthma. Curr Opin Allergy Clin Immunol 2009; 9: 128-35.

36. Ciprandi G, Caimmi D, Giudice M, et al. Recent developments in united airways disease. Allergy Asthma Immunol Rev 2012; 4: 171-7.

37. Badorrek P, Dick M, Emmert L, et al. Pollen starch granules in bronchial inflammation. Ann Allergy Asthma Immunol 2012; 109: 208-14.e6.

38. Anto JM, Sunyer J, Basagana X, et al. Risk factors of new-onset asthma in adults: a population-based international cohort study. Allergy 2010; 65: 1021-30.

39. Migueres M, Davila I, Frati F, et al. Types of sensitization to aeroallergens: definitions, prevalences and impact on the diagnosis and treatment of allergic respiratory disease. Clin Transl Allergy 2014; 4: 16.

40. Ciprandi G, Cirillo I. Monosensitization and polysensitization in allergic rhinitis. Eur J Intern Med 2011; 22: e75-9.

41. Pinart M, Benet M, Annesi-Maesano I, et al. Comorbidity of eczema, rhinitis, and asthma in IgE-sensitised and non-lgE-sensitised children in MeDALL: a population-based cohort study. Lancet Respir Med 2014; 2: 131-40.

42. Valero A, Pereira C, Loureiro C, et al. Interrelationship between skin sensitization, rhinitis, and asthma in patients with allergic rhinitis: a study of Spain and Portugal. J Investig Allergol Clin Immunol 2009; 19: 167-72.

43. Compalati E, Ridolo E, Passalacqua G, et al. The link between allergic rhinitis and asthma: the united airways disease. Expert Rev Clin Immunol 2010; 6: 413-23.

44. Duran-Tauleria E, Guedan MJ, Peterson CJ. The utility of specific immunoglobulin E measurements in primary care. Allergy 2004; 78: 35-41.

45. Yunginger JW, Ahlstedt S, Eggleston PA, et al. Quantitative IgE antibody assays in allergic diseases. J Allergy Clin Immunol 2000; 105: 1077-84.

46. Schoos AM, Chawes BL, Folsgaard NV, et al. Disagreement between skin prick test and specific IgE in young children. Allergy 2015; 70: 41-8. 